\title{
Seasonal Fluctuations in the Extent of Colonization of Avocado Plants by the Stem Canker Pathogen Phytophthora citricola
}

\author{
Zeinah A. El-Hamalawi and John A. Menge \\ Department of Plant Pathology, University of California, Riverside, CA 92521
}

Additional index words. Persea americana, amino acids, total soluble carbohydrates

\begin{abstract}
At monthly intervals, plants and stem cuttings of avocado (Persea americana Miller) 'Hass' grafted on 'Barr Duke' rootstock and 'Topa Topa' growing in a lathhouse were wounded and inoculated with the stem canker pathogen, Phytophthora citricola Sawada. The seasonal changes (measured monthly) in the extent of colonization of the avocado plants by $P$. citricola followed a periodic pattern, with two peaks of colonization during an annual growth cycle. Concentration of free amino acids and total soluble carbohydrates in the plant tissues followed a periodic pattern with two peaks similar to that of canker growth. Months were significantly different for canker size, free amino acids, and total soluble carbohydrates of the bark tissues. The extent of colonization was highest during May-June, after the first vegetative flush, and during November-December, after the second vegetative flush. Total free amino acids of the hark tissue was highly correlated with canker size $(r=\mathbf{0 . 8 9})$. Although the total soluble carbohydrate of the bark tissue was also elevated during the periods of canker development, it showed lower positive correlation $(r=0.45)$ with canker size. Plants were relatively resistant to colonization through March-April, during the first vegetative flush, and through August-September, during the second vegetative flush. Cankers formed on stem cuttings were generally larger than those of intact plants.
\end{abstract}

Avocado stem canker disease, caused by Phytophthora citricola, can be a severe disease affecting avocado in California, and it recently appears to have spread to all major avocado growing areas in California (Coffey, 1987; Coffey and Cohen, 1984). Phytophthora citricola affects the crown. lower trunk, and sometimes the main structural roots (Coffey. 1987; Zentmyer et al., 1973: Zentmyer et al.. 1974). The fungus usually invades the host at or near the soil line and grows in the inner bark tissue. It causes a canker, which may be lethal to the tree if not arrested. In advanced stages, defoliation and twig dieback occur. Phytophthora citricola attacks mature trees and also causes collar rot in young nursery trees (Coffey and Cohen, 1984). Despite its recent spread. much remains to be learned about $P$. citricola and its interaction with the tree and the environment.

Previous research has demonstrated the existence of seasonal variation in the susceptibility of deciduous trees such as apple (Gates and Millikan, 1972; Jeffers and Aldwinckle, 1986; Mircetich and Browne, 1987; Sewell and Wilson, 1973) and walnut (Matheron and Mircotich, 1985). Nondeciduous trees such as citrus (Matheron and Matejka, 1989) also exhibit seasonal variation in susceptibility to colonization by $P$. citrophthora and $P$. parasitica.

The effect of the nutritional status of the host plant on its susceptibility to infection with Phytophthora spp. was reviewed by Hohl (1983). He indicated that the nutritional status of the host plant might be a factor that influenced resistance to disease. especially horizontal resistance. Treatments that lowered the concentration of amino acids reduced the susceptibility of potatoes to infection by $P$. infestans (Grainger, 1956; Grainger, 1962; Warren et al., 1973). Hoitink et al. (1986) showed a direct correlation between the nitrogen concentration in leaf tissue of the rhododendron cultivar Roseum Elegans and susceptibility to Phytophthora dieback. Warren et al. ( 1973) reported that the levels of carbohydrates in potato plants also played a role in susceptibility to infection by Phytophthora species.

Avocado is nondeciduous tree with distinct seasonal growth patterns (Whiley et al., 1988) associated with nutrient cycling. Nutrient reserves are the highest during the season when vegetative growth is minimal. Reproductive growth and vegetative flushes lead to depletion of tree reserves (Scholefield et al., 1985). Seasonal changes in the nitrogen concentration in avocado leaves have been investigated by Bar et al. (1987). They found that the nitrogen concentration was high in the spring, the first phase of leaf growth, and was the highest in leaves of the summer flush. Koo and Young (1977) found that nitrogen was higher and calcium was lower in the leaves of the second vegetative flush compared with leaves of the first vegetative flush.

The purposes of this research were to 1) examine the seasonal variation in extent of colonization of avocado bark tissue by $P$. citricola and 2) determine the correlation between the extent of pathogen colonization (as determined by canker size) and the nutritional status of the plant (as determined by free amino acid and total soluble carbohydrate contents of phloem tissue). This knowledge is critical for determination of optimum periods for application of fungicides or other disease-control measures.

\section{Materials and Methods}

Plant material. Seedlings of Persea americana 'Topa Topa' were grown in UC \#4 soil mix (Matkin and Chandler, 1957) in plastic liners $(6 \times 12 \mathrm{~cm})$ with perforated bases for drainage. After 6 weeks of growth in the greenhouse at $24 \pm 2 \mathrm{C}$, seedlings were transplanted into 8-liter pots containing the same soil mix. The plants were maintained in the lathhouse for 1.5 years before being used in the study. Three-year-old trees of the avocado 'Hass' grafted on 'Barr Duke' rootstock were obtained from Brokaw Nursery, Saticoy, Calif., and maintained in the lathhouse before use. Plants and 20-cm-long stem cuttings of 'Topa Topa' and 'Hass' were used to evaluate the seasonal variation in extent of colonization by the stem canker pathogen, P. citricola. The lathhouse 
conditions closely resemble outdoor conditions, especially in regard to temperature and day length, and the light intensity was only reduced by $15 \%$ compared to outdoor conditions as measured by a photometer (model LI-189; LI-COR, Lincoln, Neb.).

Preparation of inoculum and inoculation method. The isolate of $P$. citricola used in the study (cc-6) was obtained originally from an infected avocado tree and is maintained in the culture collection of the Dept. of Plant Pathology, Univ. of California, Riverside. The stock culture was maintained on slants of V8C agar medium (per liter: Campbell V8 juice clarified by centrifugation, $200 \mathrm{ml}$; $\mathrm{CaCO}_{3}, 2 \mathrm{~g}$; agar, $15 \mathrm{~g}$; deionized water, $800 \mathrm{ml}$ ) and stored in the dark at $18 \mathrm{C}$. Fresh cultures were grown on V8C agar dishes at $24 \mathrm{C}$ in the dark to establish uniform colonies. Phytophthora citricola was reisolated monthly from colonized 'Topa Topa' bark tissue to maintain its virulence. and the identity of $P$. citricola was confirmed microscopically using the revised key of Stamps et al. ( 1990)

Intact or excised stems were inoculated by removing a 4-mmdiameter disc from the bark with a corkborer to expose the cambium, and then a V8C agar plug containing mycelium of $P$. citricola was placed on the exposed cambium. The wound was moistened with a drop of water after inoculation and wrapped with a strip of Parafilm to avoid drying.

Disease assessment. Intact and excised stems of 'Topa Topa' and 'Hass' plants were used to assess the seasonal fluctuation in the extent of colonization of avocado phloem tissue by $P$. citricola. The experiment was conducted in a lathhouse and repeated at the same time in another lathhouse. In each experiment, at the beginning of each month from January through December 1992, five plants from each of the avocado cultivars were inoculated and kept in the lathhouse and another five plants were used as stem cuttings, inoculated, then incubated at 20C in moist chambers. Agar discs without mycelium were placed on wounds of a set of noninoculated control plants and stem cuttings. The extent of colonization was assessed 2 weeks (plants) or 7 to 10 days (excised stems) after inoculation by measuring the canker area. Cankers were traced on transparent adhesive tape and transferred to a white sheet of paper. The area of the canker was determined by tracing the outline using a compensating polar planimeter (no. 62 0005; Keuffel \& Esser Co., Los Angeles). The size of the inoculation site was subtracted to give the canker size. To confirm that the developed cankers resulted from infection by $P$. citricola, samples taken from the canker tissues of infected plants were plated onto PARPH medium, which is selective to Phytophthora spp. (Mitchell et al., 1986). Isolation was also made from inoculated tissue, which did not develop canker to check for survival of pathogen until the conditions conducive for colonization returned. Identification of these cultures was based on the method of Stamps et al. ( 1990).

Determination of total soluble carbohydrates and free amino acids. At monthly intervals, samples from the bark of plants of both cultivars were chemically analyzed for total soluble carbohydrates and free amino acids. Twenty grams of bark collected from each plant $(15 \mathrm{~cm}$ above soil line) was cut into small pieces, frozen with liquid nitrogen, ground (60 mesh), and air dried. The dried samples were extracted with acetone in a Soxhlet apparatus to remove lipids and colored plant materials such as chlorophyll that might interfere with chemical determinations. Two grams of the defatted samples was extracted with $200 \mathrm{ml}$ of $(80 \% \mathrm{v} / \mathrm{v})$ ethanol in a water bath at $100 \mathrm{C}$ for $2 \mathrm{~h}$ under a reflux condenser. The ethanol was evaporated under vacuum and the solution was adjusted to a known volume. Aliquots of the extract were used for soluble carbohydrate determination using the anthrone method as described by Allen et al. (1974). Results were calculated as milligram glucose equivalents per gram of dry sample using glucose as a standard. The free amino acid content was determined in the same extract using the ninhydrin method as described by Fry (1988). The results were calculated as milligram leucine equivalents per gram dry tissue using the amino acid leucine as a standard. Bark samples from five plant replicates for each of the two experiments were chemically analyzed each month.

Effect of ambient temperature on seasonal colorization of avocado by $\mathrm{P}$. citricola. The correlation between ambient temperatures and P. citricola colonization of avocado for the 12 months duration of the study was determined using Univ. of California climatological data. The correlation between mean temperature and the extent of colonization of the bark by $P$. citricola was determined using correlation analysis.

Statistical analysis. Analyses of variance were performed using a completely randomized design to test for effects of month of inoculation. experiment, and interaction for each cultivar separately. Canker size plus 1.0 and the total free amino acids were transformed to logarithms to stabilize the variance. Transformation was not necessary for total soluble carbohydrates because variability between replicates was homogenous across months and experiments. Months with no cankers were not used in the calculation of error terms for testing canker size. The periodic or Fourier curve regressions (Little and Hills, 1978) were performed, using monthly means, to test for seasonal effects. The periodic curve relates the dependent variable to time and is useful for any kind of data that show seasonal effects. The period. in this cast, is a year. The independent variables are sines and cosines of the time variable, months, converted to angles measured in radians by expressing each month as a fraction of a year times two pi. For example, March is $(3 / 12)(2)(3.1416)=1.5708$ radians. The inclusion of sine and cosine of twice this angle. as well as just sine and cosine of the angle, allows the periodic curve to fit two episodes of increased biologic activity during 1 year. Correlations of total free amino acids and total soluble carbohydrates with canker size were calculated. All statistical analyses were performed with the SAS program (SAS Institute, Cary, N.C.) and significant differences among means were determined at $P \leq 0.05$.

\section{Results}

Seasonal colorization of intact avocado plants by P. citricola. The colonization of avocado plants by $P$. citricola was expressed as canker size in square centimeters. The analysis of variance showed that months were significantly different for canker size $(P$ $\leq 0.05$ ). There were no significant differences between experiments, nor were there any significant interactions of month with experiment. The seasonal fluctuation of canker size was best described by a periodic pattern. The periodic curve regression of canker size with month was highly significant $(P \leq 0.05)$ and included at least one term using twice the angle, indicating two peaks of high fungal colonization per year. For canker size on plants, the respective values for $R^{2}$ were 0.685 and 0.744 for 'Hass' and 'Topa Topa', respectively. The cankers on 'Hass' and 'Topa Topa' plants inoculated with $P$. citricola. did not increase in size during March-April and August-October: however. the size of stem canker enlarged significantly during May-June and November-December (Fig. 1). The colonization of all avocado plants was significantly greater in May than in June $(P \leq 0.05)$. Cankers that developed on the stem during January-February were significantly smaller than those developed during either May-June or November-December $(P \leq 0.05)$. In the January-February inoculation, the cankersdid notexpand but increased in size later in May. 

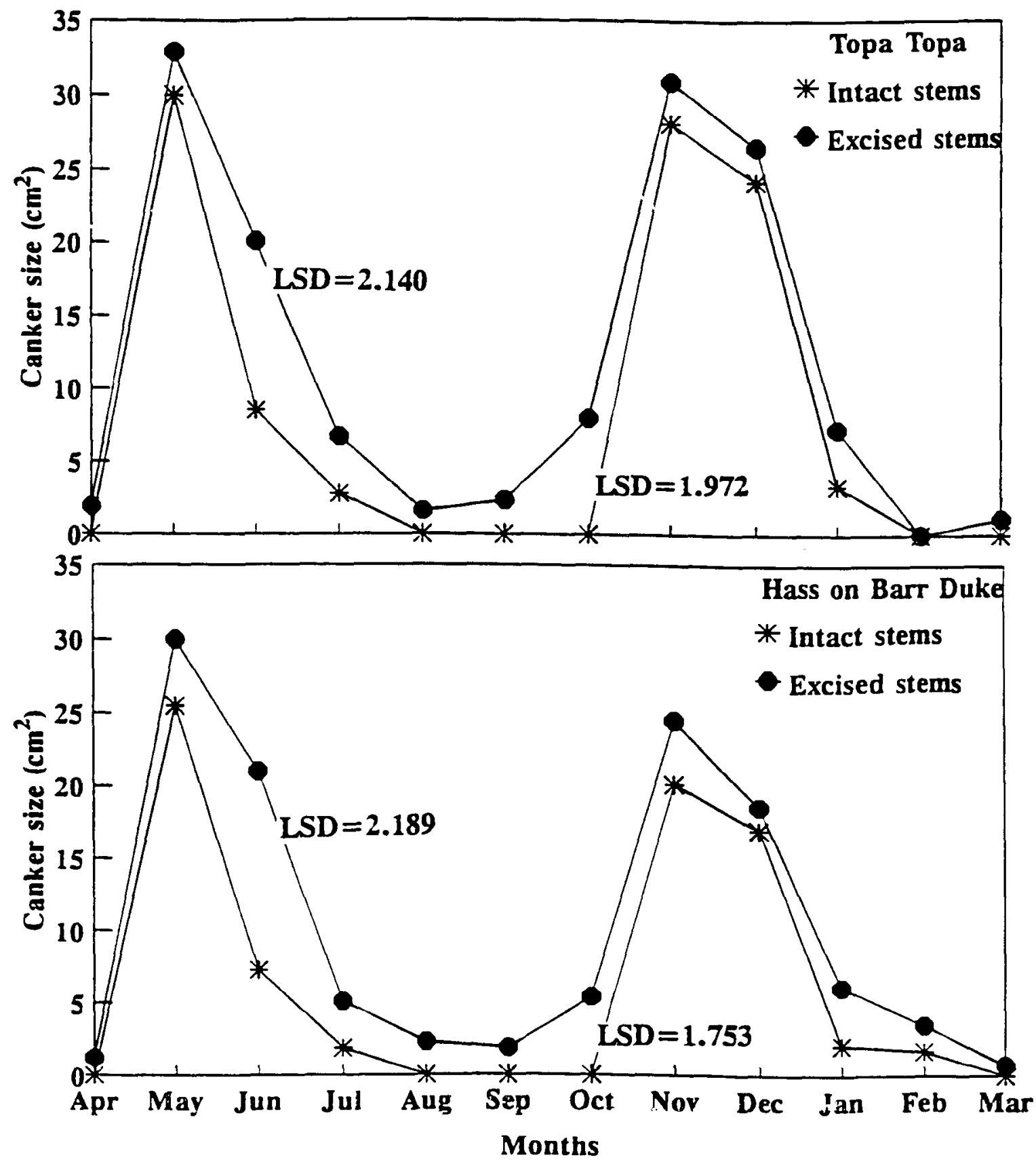

Fig. 1. Monthly fluctuation in mean canker size on intact and excised stems of avocado plants from seedling 'Topa Topa' and 'Hass' grafted on 'Barr Duke' rootstock. In each experiment, each of five plants and five excised stems of 'Topa Topa' and 'Hass' was inoculated monthly with a V8C agar plug containing mycelium of Phytophthora citricola Canker size was measured 2 weeks (plants) or 7 to 10 days (excised stems) after inoculation.

Effects of season on colonization by $P$. citricola were similar in 'Hass' and 'Topa Topa' plants.

Seasonal colonization of excised stems by P. citricola. The monthly fluctuation in colonization of stem cuttings from 'Hass' and 'Topa Topa' plants by $P$. citricola followed the same periodic pattern as that of plants (Fig. 1), and values for $R^{2}$ were 0.739 and 0.932 for 'Hass' and 'Topa Topa' cuttings, respectively. The analysis of variance showed that the months were highly significantly different for canker size on excised stems for both avocado cultivars $(P \leq 0.05)$. The periods with the highest degree of colonization by $P$. citricola were during May-June and November-December. The periods with moderate degree of colonization were January-February and July, while the periods with the lowest degree of colonization were March-April and August-October.
There was a significant difference in canker sizes developed during May compared with that in June.

Free amino acid content of the bark tissue of avocado plants. Chemical analysis revealed the presence of significantly different levels of free amino acids during the 12-month period $(P \leq 0.05)$. There were no significant differences between experiments nor were there any significant interactions of month with experiment. The level of amino acids in the bark tissue of avocado plants was highest during the periods of May-June and October-December. The lowest levels of amino acids were found during the MarchApril and July-September periods (Fig. 2). The trend of the fluctuation of the levels of free amino acids followed a periodic pattern with two peaks of high levels of free amino acids and values for $R^{2}$ were 0.826 and 0.827 for 'Hass' and 'Top Topa' plants, 

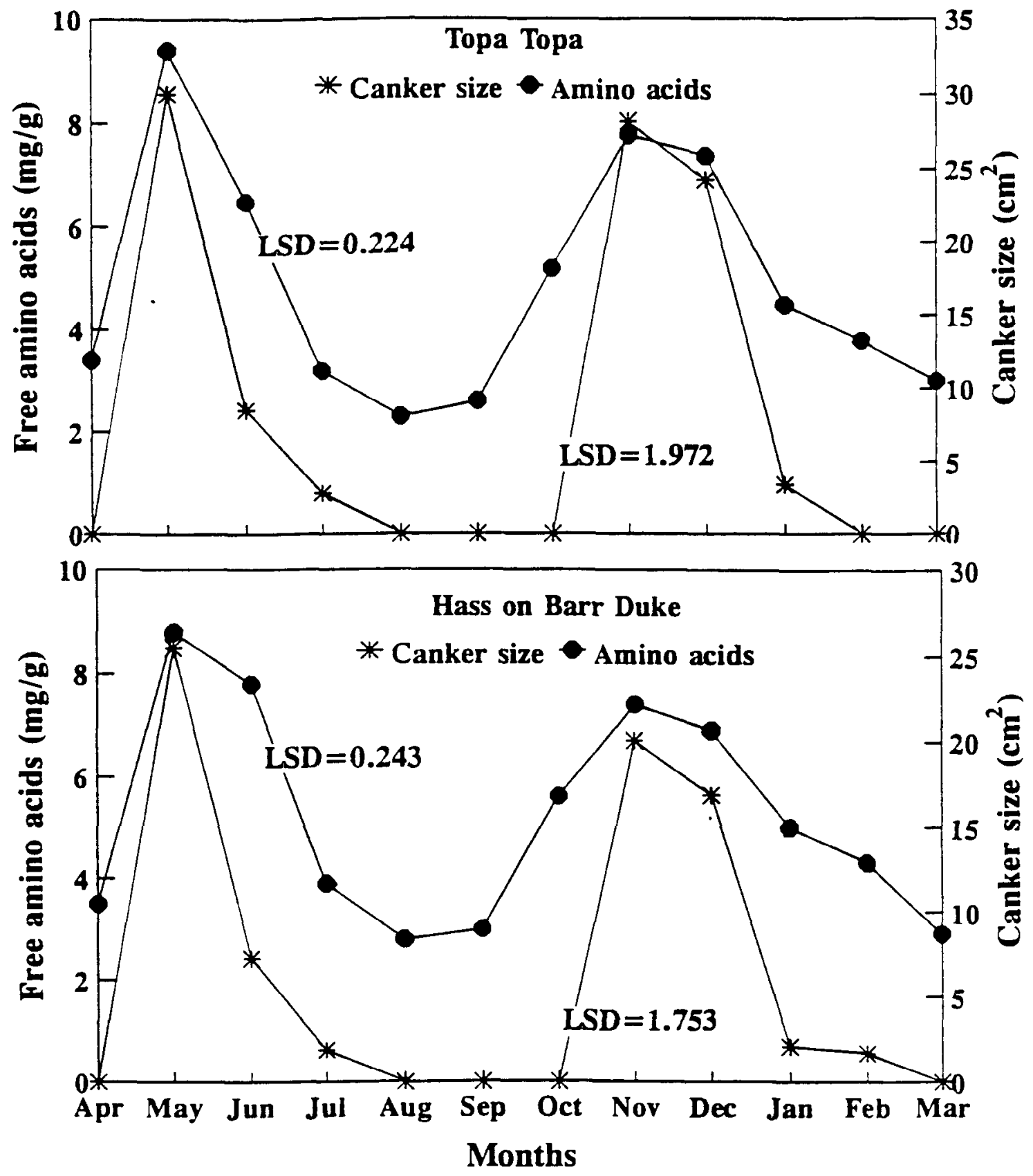

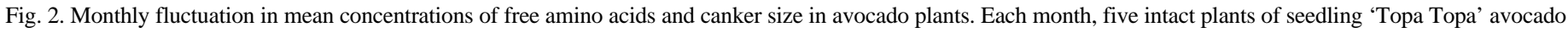
plant and 'Hass' on 'Barr Duke' rootstock were inoculated with V8C agar plugs containing mycelium of Phytophthora citricola and free amino acids measured in the bark tissue of trunks. Canker size was measured 2 weeks after inoculation.

respectively. The canker size and free amino acid content in the bark showed strong positive correlation $(r=0.89)$.

Total soluble carbohydrate content of the bark tissue of avocado plants. The level of total soluble carbohydrates in the bark was the highest during May-August and November-December (Fig. 3). There was a moderate level of total soluble carbohydrates during September-October and January-February; the lowest levels occurred in March-April. The seasonal fluctuation of total soluble carbohydrates followed a periodic pattern with two peaks of high levels during the 12-month period with $R^{2}$ values of 0.941 and 0.820 for 'Hass' and 'Topa Topa' plants, respectively. There was low positive correlation $(r=0.45)$ between canker size and total soluble carbohydrates of the bark.

Seasonal variation of ambient temperature. The statistical analysis indicated low positive correlation (0.28) between mean temperature during the 12-month period and the extent of colonization of the bark of the avocado plants by $P$. citricola.

\section{Discussion}

The extent of colonization of 'Hass' and 'Topa Topa' plants by the stem canker pathogen, $P$. citricola, varies greatly in different seasons of the year. Months were significantly different for the extent of colonization, content of free amino acids and total soluble carbohydrates $(P \leq 0.05)$. Avocado plants of both cultivars used in the study were highly colonized by $P$. citricola during May-June and November-December. The content of free amino acids and total soluble carbohydrates in the avocado bark was also high 

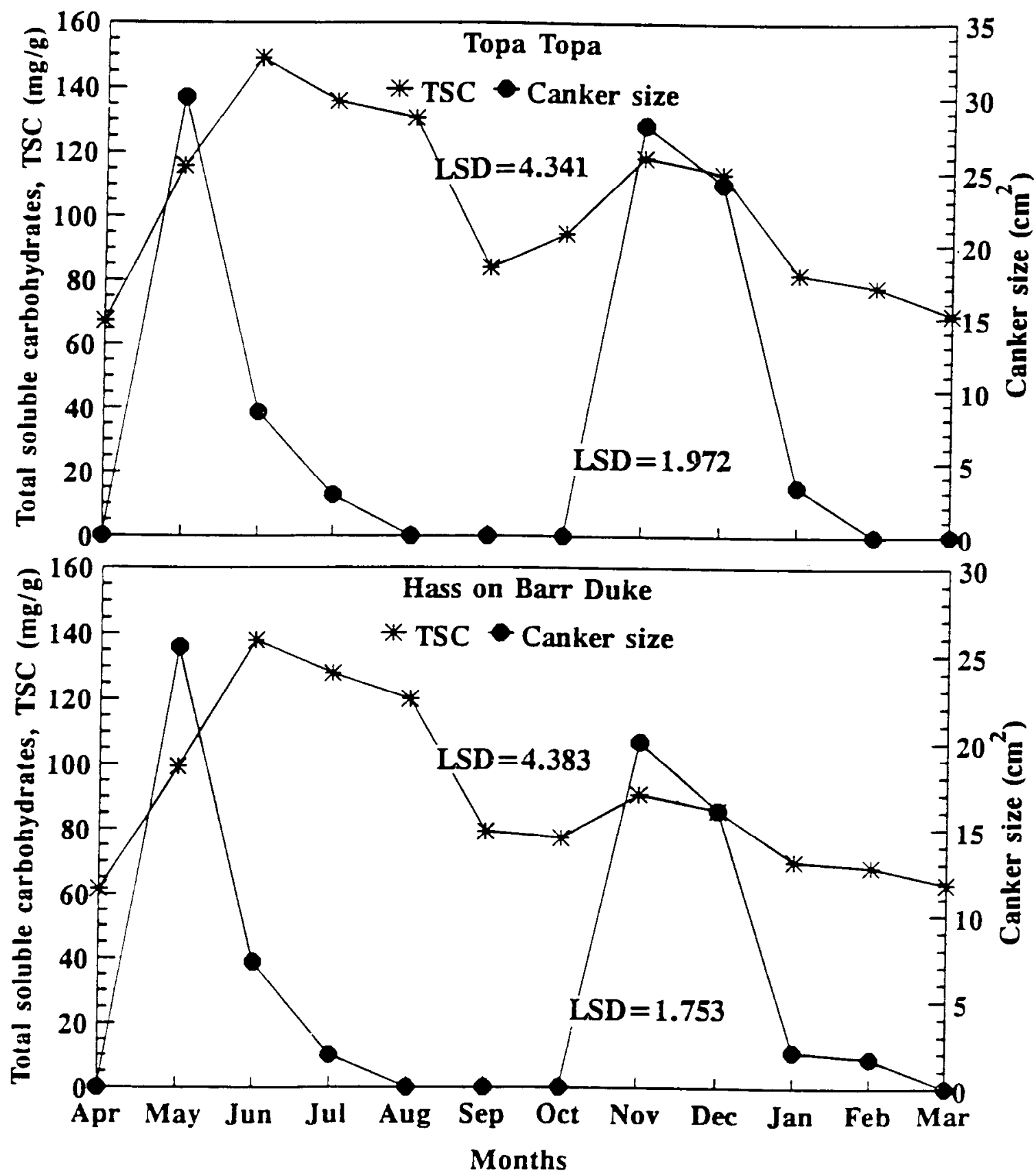

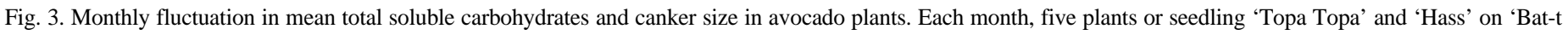

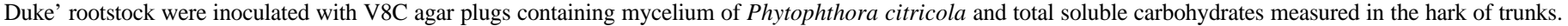
Canker size was measured 2 weeks after inoculation.

during these periods. The level of free amino acids present in the bark was positively correlated with the degree of colonization of the bark by $P$. citricola $(r=0.89)$. Monthly fluctuations in canker size and free amino acids followed the same periodic pattern, with two peaks of high levels of free amino acids and high degree of fungal colonization. Enhanced root growth occurs during these two periods (Whiley et al., 1988). This requires a high translocation activity of photoassimilates from leaves to the root system through the phloem to meet the demand for new root growth (Whiley et al., 1988). The high levels of carbon-based nutrients in the bark tissues may provide favorable conditions for pathogen establishment and stem canker development. The increase in concentration of nitrogen in the juvenile foliage of the rhododendron cultivar (Roseum Elegans) was also significantly and posi- tively correlated with size and number of lesions caused by $\mathrm{P}$. cactorum (Hoitink et al., 1986). Low numbers of small lesions were produced on nitrogen-deficient rhododendrons. Gates and Millikan (1972) showed that the susceptibility of inner bark tissues of apple to colonization by $P$. cactorum differs with season. The highest susceptibility to canker formation occurred at or near the blossoming period in May. This is also in agreement with our findings.

Cankers did not form after trees were inoculated with $P$. citricola during March-April and August-September 1992, even though $P$. citricola was recovered from inoculated sites. The weak correlation between the mean temperature during the year and canker size indicates that the failure of infection to occur was not due to unfavorable environmental conditions. rather to physiologi- 
cal and nutritional factors in the plant. Since P. citricola primarily colonizes the bark tissues of avocado plants, it seems logical that the amounts of free amino acids and total soluble carbohydrates in the bark tissue might reflect the physiological condition that would affect plant resistance or susceptibility. The significantly lower levels of free amino acids during March-April and July-September were correlated with the absence of cankers. The carbohydrate content of the bark tissue was also significantly lower during March-April, but was higher during July-September, which indicates that the level of the free amino acids may have been the critical factor that favored colonization and canker expansion by $P$. citricola. It is apparent from this study that the severity of stem canker caused by $P$. citricola is related to the growth cycle of avocado trees. Avocado plants show two major vegetative flushes in a full growth year. Each growth flush is followed by a period of enhanced root growth. The first vegetative flush begins in the spring near the end of the flowering period, while the second flush occurs during the summer (Scholefield et al., 1985; Whiley et al., 1988), which would lead to the depletion of tree nutrient reserves. Horsfall and Dimond ( 1957) stated that the development of new leaves decreases the sugar content in the vascular tissues.

Disease severity, as measured by the size of cankers on stem cuttings inoculated with $P$. citricola, was similar but did not always correspond to the relative susceptibility of plants in the lathhouse. In most cases, lesions on excised stem cuttings were larger than those on the plants. No infection occurred on plants during March-April and August-October, while lesions developed on the stem cuttings during the same periods. The resistance of the excised phloem tissue to colonization by Phytophthora may be altered by changes in the physiology of the tissue brought about by detachment from the growing plant (Matheron and Matejka, 1989). Also relatively low temperatures during January-March $(<10 \mathrm{C})$ and relatively high temperatures during August-September (>35C) may play some role in inhibiting canker development on plants during these periods. Since stem cuttings were incubated at $20 \mathrm{C}$ in the laboratory, temperatures were obviously not limiting for canker production under these conditions. Caution should be exercised when relying primarily on excised stem inoculation data for the determination of relative resistance.

Understanding that the colonization of avocado phloem tissue by $P$. citricola is affected by seasonal changes could enhance disease control by indicating optimum periods for application of fungicides. Since $P$. citricola infects through wounds such as those caused by sucker shoot removal (El-Hamalawi and Menge, 1994), care should be taken not to remove sucker shoots during periods of maximum susceptibility (May-June and October-December).

\section{Literature Cited}

Allen, S.E., H.M. Grimshaw, J.A. Parkinson, and C. Quarmby. 1974. Chemical analysis of ecological materials. Wiley, New York.

Bar, Y., E. Lahav, and D. Kalmar. 1987. Seasonal changes in nitrogen concentration in avocado leaves associated with leaf age and fertilization regime. S. Africa Avocado Growers Assn. Yearbook 10:57-58.

Coffey. M.D. 1987. Phytophthora root rot of avocado: An integrated approach to control in California, Plant Dis. 71:1046-1052.

Coffey, M.D. and Y. Cohen. 1984. Crown and collar rot of avocado: A need for more research. Calif. Avocado Soc. Yearbook. 6X:69-74.

El-Hamalawi, Z.A. and J.A. Menge. 1994. Avocado trunk canker disease caused by Phytophthora citricola: Investigation of factors affecting infection and disease development. Plant Dis. 78:260-264.
Fry, S.C. 1988. The growing plant cell wall: Chemical and metabolic analysis. Wiley, New York.

Gates, J.E. and D.F. Millikan. 1972. Seasonal fluctuation in susceptibility of the inner bark tissues of apple to colonization by the collar rot fungus, Phytophthora cactorum. Phytoprotection 53:76-81.

Grainger, J. 19.56. Host nutrition and attack by fungal parasites. Phytopathology 46:445-456.

Grainger. J. 1962. The host plant as a habitat for fungal and bacterial parasites. Phytopathology 52:140-150.

Hohl, H.R. 1983. Nutrition of Phytophthora, p. 41-54. In: D.C. Erwin, S. Bartnicki-Garcia. and P.H. Tsao (eds.). Phytophthora: Its biology, taxonomy, ecology, and pathology. Amer. Phytopathol. Soc., St. Paul, Minn.

Hoitink, H.A.J., M.E. Watson, and W.R. Faber. 1986. Effect of nitrogen concentration in juvenile foliage of rhododendron on Phytophthora dieback severity. Plant Dis. 70:292-294.

Horsfall, J.G. and A.E. Dimond. 1957. Interactions of tissue sugar, growth substances, and disease susceptibility. Z. Pflanzenkrank. (Pflanzenpathol.) und Pflanzenschutz 64:415-421.

Jeffers, S.N. and H.S. Aldwinckle. 1986. Seasonal variation in extent of colonization of two apple rootstocks by five species of Phytophthora. Plant Dis. 70:941-945.

Koo, R.C.J. and T.W. Young. 1977. Effects of age, position and fruiting status on mineral composition of Tonnage avocado leaves. J. Amer. Soc. Hort. Sci. 102:311-313.

Little. T.M. and F.J. Hills. 1978. Agricultural experimentation: Design and analysis. Wiley, New York.

Matheron, M.E. and J.C. Matejka. 1989. Temporal changes in susceptibility of citrus phloem tissue to colonization by Phyrophthora citrophthora and $P$. parasitica. Plant Dis. 73:408-411

Matheron, M.E. and S.M. Mircetich. 1985. Seasonal variation in susceptibility of Juglans hindsii and Paradox rootstock of English walnut trees to Phytophthora citricola. Phytopathology 75:970-972.

Matkin, O.A. and P.A. Chandler. 1957. The U.C.-type soil mixes. p. 6X85. In: K.F. Baker (ed.). The U.C. system for producing healthy container-grown plants. California Agr. Expt. Sta., Ext. Serv.

Mircetich. S.M. and G.T. Browne. 1987. Phytophthora root and crown rot of deciduous fruit trees: Progress and problems in etiology, epidemiology and control, p. 64-95. In: N.E. Looney (ed.). Challenges and opportunities in fruit production and utilization research. Proc. Summerland Res. Sta. Commem. Symp., Summerland, B.C. Canada.

Mitchell, D.J., M.E. Kannwischer-Mitchell. and G.A. Zentmyer. 19X6. Isolating, identifying and producing inoculum of Phytophthora spp. p. 63-66. In: K.D. Hickey (ed.). Methods for evaluating pesticides for control of plant pathogens. Amer. Phytopathol. Soc., St. Paul, Minn.

Scholefield, P.B., M. Sedgley. and D.McE. Alexander. 1985. Carbohydrate cycling in relation to shoot growth, floral initiation and development and yield in the avocado. Scientia Hort. 25:99-110.

Sewell, G.W.F. and J.F. Wilson. 1973. Phytophthora collar rot of apple: Seasonal effects on infection and disease development. Ann. Appl. Biol. 74:149-158

Stamps, D.J., G.M. Waterhouse, F.J. Newhook, and G.S. Hall. 1990. Revised tabular key to the species of Phytophthora. Mycol. Papers 162. C.M.I., Kew, Surrey.

Warren, R.C., J.E. King, and J. Calhoun. 1973. Reaction of potato plants to Phytophthora infestans in relation to their carbohydrate content. Trans. British Mycol. Soc. 61:95-105.

Whiley, A.W., J.B. Saranah, B.W. Cull, and K.G. Pegg. 1988. Manage avocado tree growth cycles for productivity gains. Queens. Agr. J. 114: 29-36.

Zentmyer. G.A., L. Jefferson, and C.J. Hickman. 1973. Another species of Phytophthora on avocado in California. California Avocado Soc. Yearbook 56: 125-129.

Zentmyer, G.A.. L. Jefferson, C.J. Hickman, and Y. Chang-Ho. 1974 Studies of Phytophthora citricola isolated from Persea americana. Mycologia 66:830-845. 